Est Ag 45 (2008) 59-82

\title{
La Ordenación Sacerdotal de San Agustín
}

\section{A propósito del año sacerdotal convocado por Benedicto XVI}

Las siguientes páginas están escritas desde el presupuesto de que la Iglesia católica norteafricana de finales del siglo IV y comienzos del V sufría agudamente el problema de la escasez de vocaciones. En ese sentido se pueden interpretar algunos datos conocidos. El primero, el haber tenido que recurrir a una persona de lengua griega que tenía dificultades con la lengua latina, Valerio, para ordenarlo como obispo de Hipona; otro, la forma en que fue ordenado san Agustín de presbítero, y el hecho de que Valerio tuviera que esconderlo, cuando ya era presbítero, temiendo que se lo quitasen para alguna otra iglesia que careciese de sacerdote $^{1}$; un tercero, la facilidad con que se ordenaba de presbíteros a monjes desertores de su monasterio ${ }^{2}$. En todo caso, es un dato confirmado por cánones de los concilios de Hipona del año 393 y de Cartago del año $401^{3}$.

1 Possidius, Vita Augustini, 8,1.

2 Ep. 60,1. Sobre la ordenación de monjes, cf. J. GAUDEMET, L'Eglise dans l'Empire romain [IVe-Ve siècles], Paris 1958, pp. 106.

3 En el último de los concilios mencionados, el primado, Aurelio de Cartago, dirigiéndose a la asamblea, advierte sobre la gran escasez de clérigos que había y sobre el hecho de que muchas iglesias estaban tan desamparadas que no disponían ni de un diácono, ni aun iletrado; añade, además, que la dificultad de encontrar ministros para los grados superiores era aún mayor. "Ya no somos capaces de soportar los lamentos de diversas comunidades casi muertas ya" (cf. Concilia Africae A. 345-A. 525, CChr 149, Turnoult 1974, pp. 43; 194-195). Cf. R. CRESPIN, Ministère et sainteté. Pastorale du clergé et solution de la crise donatiste dans la vie et la doctrine de saint Augustin, Paris 1965, pp.55ss; L. Cilleruelo, El monacato de san Agustín, Valladolid 1966, pp. 170-174. 


\section{El caso de Agustín: su ordenación como presbítero}

Quien conoce, al menos en sus rasgos esenciales, la biografía de san Agustín conoce también las circunstancias de su ordenación presbiteral, acontecimiento importante para la vida personal del santo, para la historia de la cristiandad africana y para la historia de la cultura latina cristia$\mathrm{na}^{4}$. Para algún estudioso, el hecho fue en un sentido tan esencial como el del jardín ${ }^{5}$. Información sobre él nos la ofrece el mismo san Agustín y su biógrafo san Posidio; aquel en el célebre sermón $355^{6}$, éste en el capítulo cuarto de su Vida de Agustín.

El sermón 355 lo predicó Agustín ya al final de su vida, el 18 de diciembre del 425. El motivo fue el escándalo que produjo en Hipona el saber que un presbítero del monasterio de clérigos de Agustín había hecho testamento, quebrantando así el compromiso de tener todo en común. El obispo convocó a la comunidad católica para presentarle el ideal que intentaban vivir, comentar el caso del presbítero desde esa perspectiva y anunciar una investigación en toda regla al conjunto de los clérigos del monasterio, de cuyo resultado daría cuenta poco después, en el sermón 356. El sermón contiene datos biográficos, entre los que figuran cómo arribó a Hipona y cómo llegó al presbiterado:

"Yo, en quien por benevolencia de Dios veis a vuestro obispo, vine siendo aún joven a esta ciudad. Muchos de vosotros lo sabéis. Buscaba dónde fundar un monasterio en el que vivir con mis hermanos. Había abandonado toda esperanza mundana, y no quise ser lo que hubiera podido ser; en todo caso, no busqué lo que soy. Preferí vivir postergado en la casa de Dios a habitar en una tienda de pecadores (Sal 83,11). Me separé de quienes aman el mundo, pero no me equiparé a los que gobiernan los pueblos. No elegí un puesto más elevado en el banquete de mi Señor, sino el último y despreciable; pero le plugo a él decirme: Sube más arriba (Lc 14,10). Hasta tal punto temía el episcopado que, cuando comencé a ser conocido en mi condición de siervo de Dios, evitaba acercarme a lugares dónde sabía que carecían de obispo. Me guardaba bien de ello y gemía

4 Cf. G. MADEC, Augustin prêtre. Quelques notes pour la célébration d'un 16e centenaire, 391-1991, en Lectures Augustiniennes, Paris 2001, 59-74: 59; antes publicado en De Tertullien aux Mozarabes I, Antiquité tardive et christianisme ancien (IIIe-VIe siècles). Mélanges offerts à Jacques Fontaine, Paris 1992, 185-199.

5 A. Mandouze, Saint Augustin. L'aventure de la raison et de la grâce, Paris 1968, p. 135.

${ }^{6}$ A este texto hay que añadir la ep. 21, dirigida a su obispo Valerio. 
cuanto podía para salvarme en un puesto más humilde antes que ponerme en peligro en uno elevado. Más, según he dicho, el siervo no debe llevar la contraria a su amo. Vine a esta ciudad para ver a un amigo al que pensaba que podría ganar para Dios y llevar con nosotros al monasterio. Vine con cierta tranquilidad porque la ciudad tenía obispo, pero me apresaron, fui hecho sacerdote, y así llegue al grado del episcopado. Nada traje; vine a esta Iglesia con la sola ropa que traía puesta..."?

En los capítulos tercero y cuarto de su Vida de Agustín, san Posidio nos informa sobre las circunstancias que llevaron a san Agustín a Hipona y al presbiterado. El relato de su promoción al presbiterado es el siguiente:

"Entonces ejercía como obispo de la iglesia católica de Hipona Valerio, un santo varón. Por exigirlo la necesidad de la Iglesia, habló y exhortó al pueblo de Dios acerca de la provisión y ordenación de un presbítero para la ciudad. Entonces los católicos, que conocían ya el proyecto religioso y la enseñanza del santo Agustín, le echaron mano, pues también él se encontraba entre el pueblo, despreocupado y desconocedor de lo que iba a suceder -siendo laico, como nos decía, sólo acostumbraba negar su presencia a las iglesias que no tenían obispo-. Lo sujetaron, pues, y, como es habitual en tales casos, lo presentaron al obispo para que lo ordenase. Con unánime consenso y deseo, todos pedían con gran ardor y gritos que eso se hiciese y se realizase sobre la marcha, mientras él lloraba copiosamente. Según nos refirió él mismo, algunos vieron en sus lágrimas una señal de orgullo y, como para consolarle, le decían que la condición de presbítero, aunque él merecía más, era también un peldaño hacia el episcopado. La realidad era que aquel varón de Dios, como él nos confesó, consideraba lo sucedido desde una perspectiva más elevada y gemía teniendo a la vista cuántos y cuán grandes peligros acarrearía a su vida el regir y gobernar la Iglesia, y por eso lloraba. Y, como ellos quisieron, se cumplió su deseo" 8 .

Ambos relatos -es fácil de advertir- coinciden en lo esencial. Nada extraño considerando que san Posidio alude por tres veces a confidencias que le hizo el mismo san Agustín. Pero hay diferencias, más de complemento que de oposición. Entre otras, san Agustín pone el énfasis en su mundo interior, mientras san Posidio lo pone en el papel de la comunidad católica de Hipona ${ }^{9}$.

7 S. 355,2.

8 Possidius, Vita, 4

${ }^{9}$ Las restantes se irán señalando en su momento. 
La Vida de Agustín escrita por san Posidio es una más entre otras biografías de santos obispos de la Iglesia latina antigua ${ }^{10}$. Pero es diferente de ellas por varios aspectos, relacionados con la cronología, con el biografiado, con el biógrafo, con la relación entre ambos, con el contenido. La obra de san Posidio fue la última en el tiempo; aunque fueron personajes relevantes en la vida de la Iglesia san Cipriano, san Ambrosio y san Martín de Tours, san Agustín los supera a todos en categoría e influjo; a diferencia de los demás biógrafos, san Posidio compartía con su biografiado la condición episcopal ${ }^{11}$, y a biógrafo y biografiado les unió una amistad sincera que duró más de cuarenta años; en el escrito de san Posidio, a la vez que desaparece casi por completo el elemento milagroso, la gran parte de los datos que aporta tienen verificación externa.

Los juicios de los estudiosos sobre san Posidio en cuanto autor literario y sobre su obra, la Vida de Agustín, están lejos de ser unánimes. Juzgándole desde su obra, unos le consideran una personalidad sin relieve, otros le valoran más positivamente. En cuanto a la obra, además de su composición literaria y sus fuentes, se ponen de relieve tanto sus valores como sus defectos, sus errores, sus inexactitudes y carencias ${ }^{12}$. Pero, como suele suceder en estos casos, lo que unos estudiosos consideran incapacidad o ineptitud, otros lo juzgan consecuencia del objetivo específico que el autor se había propuesto ${ }^{13}$. Así R. Gregoire reclama no olvidar su dimensión tipológica dentro de un marco hagiográfico ${ }^{14}$. En él, a los even-

\footnotetext{
10 Nos referimos a las Vidas de San Cipriano, san Martín de Tours y san Ambrosio escritas respectivamente por Poncio, Paulino y Sulpicio Severo. Cf., Antoon A.R. BASTIAENSEN (Ed.), Vita di Cipriano, Vita di Ambrogio, Vita di Agostino. Introduzione di C. Mohrmann. Testo critico e commento a cura di A.A.R. Bastiaensen. Traduzione di L. Canali e C. Carena, Verona 1975, ${ }^{21981 ; ~ S . ~ S E V E R U S, ~ V i e ~ d e ~ S a i n t ~ M a r t i n, ~ I n t r o d u c t i o n, ~ t e x t e ~ e t ~ t r a d u c t i o n ~ p a r ~ J . ~}$ Fontaine, Sources Chrétiennes 133-135, Paris 1967-1969.

11 Poncio, el biógrafo de san Cipriano y Paulino, el de san Ambrosio eran sólo diáconos; Sulpicio Severo, el de san Martín de Tours, laico.

12 Cf. E. Elm, Die Macht der Weisheit. Das Bild des Bischofs in der Vita Augustini des Possidius und anderen spätantiken und frühmittelalterlichen Bischofsviten, Leiden/Boston 2003. En la introducción, la autora recensiona los estudios más importantes sobre la Vita Augustini de san Posidio. Coincide básicamente con otro artículo de la autora, publicado pocos años antes: Die Vita Augustini des Possidius: The work of a plain man and an untrained writer? Wandlungen in der Beurteilung eines hagiographischen Textes, en Augustinianum 37 (1997) 229-240. Al ser más antiguo, en él no son recensionados artículos que sí aparecen en el libro. Cf. también, Erika T. Hermanowwicz, Possidius of Calama. A Study of the North African Episcopate. Oxford University Press 2008, pp. VII-IX; 17-80.

13 Cf. E. Elm, Die Macht der Weisheit, 13: "Die Betrachtung der älteren Bischofsviten, der ihnen zur Verfügung stehenden formalen und thematischen Vorbilder, ihrer spezifischen Bedürfnisse und Intentionen und der von ihnen gewählten literarischen Gestalt liefert eine Erklärung für Phänomene, die an der Vita des Possidius kritisiert wurden, die Statik des
} 
tos históricos de que ha tenido conocimiento directo o indirecto, san Posidio añade un "al di là", porque demuestra el logro de una realización como persona humana, que tuvo lugar en el encuentro con Dios ${ }^{15}$. La hagiografía se construye sobre una visión teológica de la historia. A la verdad del hecho histórico, que sirve de estructura al mensaje doctrinal, hay que sumar la verdad del tema doctrinal, ofrecido a través de la mediación de precisas situaciones en que el santo está implicado en modo concreto ${ }^{16} \mathrm{M}$. Pellegrino, a su vez, pone de relieve la "aguda mentalidad eclesiástica común a la hagiografía antigua" 17 . Esto significa que los detalles que puedan exceder la historicidad esencial, tienen también valor como testimonio de una concepción espiritual o eclesial que el autor quiere trasmitir. Y en este sentido es también histórica. Esto nos permite no excluir ninguno de los detalles del texto para nuestra reflexión en contexto vocacional.

En el relato de san Posidio aparecen tres protagonistas en la promoción de san Agustín al presbiterado: el obispo Valerio, la comunidad católica de Hipona y, obviamente, Agustín. El obispo propone, la comunidad dispone y Agustín accede. En el relato de Agustín, el único protagonista explícito es él mismo; presupone los demás, pero no los menciona; indica que le apresaron, pero no dice quiénes; que fue ordenado sacerdote, sin indicar tampoco por quién.

\section{a) El obispo Valerio}

San Posidio atribuye la iniciativa de la ordenación presbiteral de Agustín a Valerio, obispo de la ciudad de Hipona, aunque sólo indirectamente. En efecto, suya fue sólo la propuesta de ordenar un presbítero

Erklärung für Phänomene, die an der Vita des Possidius kritisiert wurden, die Statik des Beschreibung, das Fehlen charakterlicher und seelischer Entwicklung, das geringene Interesse an der eigentlichen Persönlichkeit des protagonisten, die Typisierung der Contrahenten sowie die unhistoriche Gestaltung der Jugend und des Bekehrungserlebnisses. Sie kann das Bild des naiven, geistig mediokren und von Augustinus gänzlich abhängigen Biographen relativieren und deutlich machen, das die Veränderungen, die Possidius gegenüber den Confessiones vorgenomen hat, nicht auf seine 'Unfähigkeit' zurückzuführen sind, sondern einem bewussten Gestaltungswillen entsprechen und aus den spezifischen Entstehungsbedingungen der Bischofsbiographie zu erklären sind, ja in gewissem Ausmass mit Augustins eigenen theologischen Vorstellungen übereinstimmen".

14 Cf. R. Grégoire, Riflessioni sulla tipologia agiografica della "Vita Augustini" di Possidio, en Augustinianum 25 (1985) 21-26: 21.

15 R. GREGOIRE, Riflessioni 26.

16 R. GregoIre, Riflessioni, 26.

17 Possidio, SAN, Vita di S. Agostino. Introduzione, testo critico, versione e note a cura di M. Pellegrino, Paoline 1955, p. 27. 
para la ciudad. Ignoramos si, al hacerla, pensaba ya en el asceta de Tagaste cuya presencia allí podía haber advertido. El relato de san Posidio nada dice al respecto. El biógrafo indica las razones que impulsaron su iniciativa, vinculándola a su santidad ${ }^{18}$. De forma explícita, señala qué le movió a actuar -la necesidad de la grey que pastoreaba-, en qué consistió su actuación -en dirigir la palabra a los fieles- y el objetivo a que iba encaminada -la provisión y ordenación de un presbítero para la ciudad-. Veamos más de cerca cada uno de estos datos.

La necesidad de su grey. "Por exigirlo la necesidad de la Iglesia", dice san Posidio. La Iglesia que pastoreaba el obispo Valerio era la comunidad católica de Hipona. El calificativo "católica" tiene en este caso un valor especificativo, pues existía otra comunidad cristiana, la donatista. La necesidad advertida por el obispo Valerio tiene que ver precisamente con la existencia de esta comunidad alternativa y hostil. El biógrafo la consideraba imperiosa al decir que reclamaba (flagitante) una intervención rápida y eficaz. En efecto, a partir de la segunda mitad del siglo IV, mientras la Iglesia católica había entrado en una fase de persistente cuarto menguante, la donatista se encontraba en una fase de continuo cuarto creciente. La Iglesia donatista aventajaba a la católica tanto en número de fieles, como en influjo social. Sólo por poner un ejemplo, era tal su fuerza en los estamentos productivos de la ciudad que había logrado que los panaderos no vendieran pan a los católicos ${ }^{19}$. Perder influjo social en general era importante para la Iglesia católica, pero más importante aún era perder significado social específicamente religioso. Su gran necesidad en aquel contexto era detener el trasvase de fieles hacia la Iglesia rival y hacia otras comunidades religiosas, de las cuales la más significativa era la maniquea. Esta secta, que también se presentaba como cristiana, hacía igualmente estragos ${ }^{20}$ en Hipona, gracias sobre todo a la labor de un presbítero de nombre Fortunato, antiguo compañero de Agustín. Lo prueba el

18 Así lo deducimos del hecho de que lo califique como santo. Este calificativo se aplicaba habitualmente en la Iglesia antigua a todos los bautizados que se mantenían en comunión con la Iglesia, tanto si eran clérigos, monjes o simples fieles. San Agustín suele dirigirse a sus fieles con el título "Vuestra santidad" (cf. ep. 126,6; 179,5; en. ps. 25,2,1.5; 33,2,9; S. 51,13; 74,3.5; etc.). Su fundamento es la santidad del sacramento del bautismo. Pero en este pasaje parece que hace referencia a un específico nivel de santidad personal; en esta dirección van los adjetivos que le aplica más adelante: vir venerandus et providus (Vita 5,4). También san Agustín habla muy elogiosamente de su obispo (cf. ep. 22,$4 ; 31,4 ; 33,4$ ).

19 Cf. C. litt. Pet. 2,83,184. El hecho, sin embargo, había tenido lugar quizá unas tres décadas antes de la llegada de Agustín a Hipona.

20 San Posidio afirma que "había contagiado a muchísimos habitantes de Hipona y forasteros" (Vita, 6). 
que, a poco de ser ordenado presbítero, los cristianos, católicos y donatistas juntos, de Hipona y de fuera de Hipona, le pidieron que debatiese con el maniqueo, petición que el aceptó de inmediato ${ }^{21}$.

Una vez sentida una necesidad, el responsable ha de buscar cómo remediarla. En unos casos se tratará de buscar medios, en otros de buscar personas; en otros, los medios pueden ser las personas mismas. Teóricamente el llamado a encabezar la reacción que necesitaba la Iglesia era el obispo. Pero él era muy consciente de su doble limitación. Una, que siendo griego de origen, no dominaba la lengua latina ${ }^{22}$, y menos aun el púnico $^{23}$, lo que representaba un muy serio obstáculo para una tarea tan importante del pastor de la Iglesia como es la predicación; otra, que, al ser ya anciano $^{24}$, le faltaban las fuerzas. Una vez que hubo tomado conciencia de la urgencia de la necesidad dio un paso importante, consistente en buscar a alguien que hiciera lo que él sabía que personalmente no estaba en condiciones de hacer.

Alocución a los fieles. San Posidio, que nos informa sobre el hecho, es más bien lacónico al respecto: "habló y exhortó al pueblo de Dios...". No nos indica ni el cuándo, ni el dónde. No obstante, el cuándo es posible deducirlo de la carta 21; el dónde, de la misma información de san Posidio. La carta 21 nos informa de que, recién ordenado, Agustín pidió a su obispo algún tiempo para entregarse al estudio de la Escritura, específicamente hasta la Pascua, que aquel año caía el 6 de abril; es lógico pensar, pues, en las primeras semanas del año $391^{25}$. Una propuesta que afectaba a la comunidad católica sólo cabía que la hiciera en el lugar y momento en que la comunidad estuviera reunida. Esto tenía lugar en la iglesia en algún sábado o domingo, presumiblemente durante la celebración de la Eucaristía, a la que asistía el mismo Agustín. El cronista Posidio utiliza dos verbos: "habló" y "exhortó". El segundo verbo tiene especial importancia porque descubre el sentido del primero. La alocución del obispo a sus fieles no consistió en una simple información, sino también en una exhortación. Tras haberles informado de lo que él consideraba una nece-

\footnotetext{
${ }^{21}$ El debate tuvo efectivamente lugar y de él poseemos las actas en la obra que lleva por título precisamente Actas del debate con el maniqueo Fortunato (cf. Obras completas de san Agustín, vol. 30, BAC 487, Madrid 1986, pp. 225-269).

22 Cf. Possidius, Vita, 5,2.

23 Cf. Ep. Rm. inch. 13.

24 Tanto san Posidio (Vita, 8,1) como san Agustín (Ep. 21,5;29,7) se refieren a él como "el anciano (senex) Valerio". La senectus comenzaba para los romanos a los 60 años.

25 Cf. Ep. 21,4. El año resulta de otro dato de san Posidio; él que habla de casi tres años de estancia en Tagaste desde su regreso de Italia (Vita, 3,2). Cf. P. LANGA, La ordenación sacerdotal de san Agustín, en Revista Agustiniana 33 (1992) 51-93: 59-60.
} 
sidad para la Iglesia, no se quedó en lo que pensaba hacer él, sino que pasó a lo que, en parte al menos, debían hacer ellos. El obispo no quería que los fieles fueran sujetos pasivos ante una necesidad de la Iglesia; al contrario, los implicó en la solución del problema.

Contenido de la alocución. La alocución y exhortación versó acerca de "la provisión y ordenación de un presbítero para la ciudad". El texto suscita algunas preguntas: ¿Se trataba de ordenar un presbítero porque el obispo no contaba con ninguno, o porque contaba con pocos, o porque los que había carecían de los requisitos adecuados para la función que se le iba a encomendar? ¿Se trataba específicamente de un presbítero para la ciudad? La primera posibilidad, que el obispo no contase con ningún presbítero colaborador en la tarea apostólica, es posible, pero no la consideramos probable. Aunque es tardía, del 426, por la carta 213 sabemos que san Agustín contaba con al menos 7 presbíteros de los que da los nombres $^{26}$.La segunda posibilidad es inverificable; la tercera es la más probable. Un hecho es claro: según san Posidio, lo que buscaba el obispo Valerio era una persona capacitada para la predicación. Eso era lo que había pedido a Dios: "El santo Valerio, que lo había ordenado, en cuanto hombre piadoso y temeroso de Dios, exultaba y daba gracias a Dios porque había escuchado sus frecuentísimas súplicas de que Dios le concediese un hombre capaz de edificar con la palabra y una enseñanza saludable la Iglesia del Señor"27. Lo confirma el hecho de que, una vez ordenado, le dio potestad para predicar el evangelio en la iglesia en su presencia y para comentarlo con mucha frecuencia, contra el uso y costumbre de las Iglesias de África, razón por la que algunos obispos le criticaron ${ }^{28}$. En este sentido puede tener importancia el "para la ciudad". Los presbíteros, de hecho, solían suplir en el campo al obispo que no podía trasladarse allí, a no ser ocasionalmente $^{29}$. Valerio quería uno nuevo específicamente para la ciudad que era donde dirimían, en el ámbito de las ideas, su batalla católicos y donatistas. La teología ha sido preferentemente urbana.

\section{b) La comunidad de fieles de Hipona}

En el relato de san Posidio, junto al obispo aparecen como protagonistas los católicos presentes en la iglesia. En el sermón 355, san Agustín no los menciona explícitamente, pues, aunque refiere su acción, calla

26 Cf. ep. 213,1; s. 356 10.11.15.

27 Possidius, Vita, 5,2.

28 Possidius, Vita, 5,3.

29 Cf. ep. 29,$12 ; 65,1-2 ; 105,3 ; 13^{*}, 3$, etc. Sobre el clero rural, cf. A. G. HAMMAN, La vida cotidiana en Africa del norte en tiempos de san Agustín, Iquitos-Madrid 1989, pp. 359-362. 
sobre los autores. Llama la atención su forma de narrar el hecho: se sirve de la forma pasiva ("fui apresado", "fui hecho sacerdote") pero sin indicar el sujeto agente. ¿Por qué actúa así el predicador? Habida cuenta de que estaba hablando a la misma comunidad que había forzado su ordenación presbiteral, bien podía haber dicho: "Vosotros me apresasteis", "a petición vuestra fui ordenado presbítero", pero renuncia a hacerlo. De este particular pueden darse varias explicaciones. Una, que se encontrase en distinto templo; el dato, aunque poco probable, es imposible de verificar $^{30}$. Otra, que pasados unos 35 años, la comunidad era ya distinta de la que había protagonizado los hechos narrados. Pero ni una ni otra parecen convincentes. La primera, porque, aunque los templos fuesen distintos, la comunidad era la misma; la segunda, porque 35 años no es un espacio temporal tan grande como para excluir que se encontrasen allí testigos de la ordenación de Agustín. Es, por otra parte, lo que cabe deducir de la afirmación previa del santo de que muchos de ellos sabían que había llegado a la ciudad cuando aún era joven. Una tercera explicación es que, en el ambiente tenso que había provocado el sermón, el obispo quiso centrarse exclusivamente en su propia persona. El problema estaba de puertas adentro y no de puertas afuera; el encausado, aunque sólo fuera indirectamente, era él, no ellos, los fieles. Cualquier referencia a los que le auparon al ministerio podía verse como un echar balones fuera.

Pero volvamos a lo que nos dice san Posidio sobre los fieles de la comunidad de Hipona en el contexto de la ordenación de Agustín. El biógrafo refiere de qué información disponían sobre él, cuál fue su actuación ante la propuesta del obispo, cuál su estado de ánimo en aquel momento y cómo intentaron consolarle. También a ellos los califica de santos, adjetivo al que hay que asignarle un valor especificativo y de epíteto a la vez. En cuanto especificativo se refiere a los católicos ya bautizados, los ya fieles, distinguiéndolos de los aún catecúmenos a los que también se les permitía asistir a la primera parte de la celebración eucarística, la liturgia de la palabra. En cuanto epíteto el adjetivo califica al conjunto de los fieles católicos; es decir, el cronista no considera que unos católicos fueran santos y otros no, sino que, fiel al uso de la Iglesia antigua, tiene por santos a todos por el hecho de estar bautizados y no haber roto la comunión con la Iglesia.

Según san Posidio, los fieles católicos de Hipona estaban al tanto del

\footnotetext{
${ }^{30}$ Una información rápida sobre los distintos templos (ya fueran basílicas, iglesias dedicadas a mártires locales o memorias) existentes en Hipona o en otros lugares de la diócesis puede verse en Nuovo Dizionario Patristico e di antichità cristiane, Marietti 1820, Genova 2007, voz Hipona, vol. 2, pp. 2606.
} 
proyecto religioso (propositum) y de la enseñanza (doctrinam) de Agustín, dos datos de relevancia para el oficio al que Valerio pensaba promocionarle. En efecto, el propositum ${ }^{31}$ hace referencia a su condición de "siervo de Dios"32 y con la doctrina a su preparación intelectual específicamente cristiana que ya había dado a conocer con su palabra y sus escri$\operatorname{tos}^{33}$. Aunque Agustín había vuelto a África hacía apenas tres años ${ }^{34}, \mathrm{y}$ aunque residía en Tagaste, a menos de cien kms. al sur de Hipona, su fama de siervo de Dios y de hombre docto en el saber cristiano había traspasado las fronteras del interior y llegado hasta la ciudad costera. Pero no lo conocían sólo de oídas, sino también de vista. Prueba de ello es que le reconocieron en medio de la asamblea litúrgica. El hecho indica la celebridad que Agustín había adquirido en la región o quizá también que visitaba con alguna frecuencia Hipona. No tenemos constancia de ninguna visita suya anterior a la ciudad portuaria; la primera conocida es la que le llevó a ser ordenado presbítero y cuyo motivo, doble, conocemos por confesión propia: buscar dónde fundar un monasterio en el que vivir con los hermanos ${ }^{35}$ y ver a un amigo al que pensaba que podía ganar para Dios o, lo que es lo mismo, para la vida monástica ${ }^{36}$. San Posidio amplía la información, señalando que se trataba de un funcionario imperial, un agens in rebus $^{37}$, y que se resistía a cumplir su anterior promesa, retrasándolo de día en día, por lo que Agustín hubo de tener repetidas entrevistas con él (frequentius) $^{38}$. Este particular implica que Agustín tuvo que trasladarse en más de una ocasión a Hipona con ese fin, o que tuvo que prolongar su

31 Sobre el propositum, cf. G. LAWLESS, An Augustine Glossary of Monastic Terms, en Homo spiritalis. Festgabe für Luc Verheijen OSA zu seinem 70. Geburtstag (hrsg. von C. Mayer/K.H. Chelius) (Cassiciacum 38), Würzburg 1987, 276-294: 291-294; A. ZuMKELleR, 'Propositum' in seinem spezifisch christlichen und theologischen Verständnis bei Augustinus, en ib. 295-310:298-304.

32 San Posidio no utiliza aquí esta denominación, pero sí san Agustín en el S. 355. Sobre "siervo de Dios" como término para designar a los ascetas y monjes, cf. G. LAwLESs, An Augustine Glossary, pp. 286-290;

33 Possidius, Vita, 3,2 .

34 Possidius, Vita, 3,2.

35 ¿Por qué pensaba en abandonar Tagaste? Cabe pensar en dos razones: porque allí ya no le dejaban en paz y porque la casa paterna se quedaba ya pequeña (cf. A. TrAPE, $S$. Agostino. L'uomo, il pastore, il mistico, Fossano 1976, p. 161; A. MANDOUZE, Saint Augustin, p. 211, n. 2).

36 San Posidio sólo aduce esta última motivación (Vita, 4,3-5).

37 Ese agens in rebus bien podía ser san Posidio mismo. Cf. E. T. Hermanowwicz, Possidius of Calama, p. 37.

38 Possidius, Vita, 3,4. Sobre este fracaso de Agustín, que él silencia en s. 355,2, cf. E. T. Hermanowwicz, Possidius of Calama, pp. 30-32. 
estancia en la ciudad ${ }^{3 y}$. En cualquiera de las dos hipótesis encontró la comunidad católica de Hipona una oportunidad para conocerle de vista porque, como siervo de Dios, no dejaría de asistir a las celebraciones litúrgicas. Tanto más que su celebridad allí era anterior a su llegada. Sólo así se entienden las ansias de hablar con él del funcionario imperial, circunstancia que llevó al monje de Tagaste a Hipona. Es, una vez más, san Posidio quien nos informa: "Por este tiempo, sucedió casualmente que cierta persona..., residente en Hipona, buen cristiano y temeroso de Dios, sintió hablar de la estima en que era tenido (Agustín) y de la enseñanza que impartía; entonces sintió un vivo deseo de verlo, prometiendo que podía renunciar a toda apetencia y placer mundano, si alguna vez tenía la dicha de oír de su boca la palabra de Dios" 40 . Aunque le podía conocer de oídas, no cabe excluir totalmente que Agustín hubiese hecho anteriormente otras visitas a Hipona, lo que alimentaría las esperanzas de ese funcionario. Además, ¿por qué buscaba el santo allí el lugar para fundar el monasterio? Quizá porque ya conocía el terreno que pisaba.

La actuación de los católicos de Hipona la describe el biógrafo de Agustín de una manera muy gráfica: "pusieron las manos sobre él,... lo apresaron y, como se usa en tales casos, lo presentaron al obispo para que lo ordenase". El mismo san Agustín se expresa de forma parecida: "me apresaron, fui hecho sacerdote, y así llegue al grado del episcopado". Hubo, pues, coacción física ${ }^{41}$, lo cual prueba que Agustín ofreció resistencia. Este procedimiento, sin duda expeditivo, era, a decir del mismo san Posidio, algo habitual: "como se usa en tales casos". En efecto, el suyo no era el único ${ }^{42}$.

A continuación el cronista alude al estado anímico de los participan-

${ }^{39} \mathrm{El}$ dato aportado por el s. 355,2 de que llegó sin otra ropa que la puesta no obsta a ello, puesto que, a menudo, los proyectos que uno se forja difieren luego bastante de la realidad.

40 Possidius, Vita, 3,3-5. Si no fuera porque san Posidio dice de él que era "buen cristiano y temeroso de Dios", se podría pensar que al personaje le movía más la curiosidad de conocer a Agustín que un auténtico deseo de hacerse siervo de Dios. Apunta en esa dirección no sólo el que Agustín fracasó en su intento de convencerle, sino también la condición que le puso: encontrarse personalmente con él. Lo normal en esos casos era que el interesado fuera quien buscase al maestro, no que el maestro le buscase a él (cf. S. DAGEMARK, Possidius's Use of the Bible: an Examination of Intertextuality in Vita Augustini, en L'esegesi dei Padri Latini. XXVIII Incontro di Studiosi dell'Antichità cristiana, Roma 1999 1. Parte Generale, Oriente, Africa, Roma 2000,175-218: 198-199). Suponemos que aún no existía la costumbre de coleccionar autógrafos de personajes famosos.

41 En la carta 21 a su obispo Valerio lo afirma expresamente (Ep. 21,2: "vis mihi facta est"; aunque no hay que pensar que se refiera a la violencia física).

42 En ep. 173,2 escribe Agustín: "Escucha qué dijo sobre esto el Apóstol: Quien desea el episcopado desea una obra buena (1 Tim 3,1). Y ya ves cuántos son retenidos a la fuerza para que acepten el episcopado. Se les lleva, se les encierra, se les custodia. Padecen tantas cosas 
tes durante la acción previamente narrada. Quiere dejar claro que no fue capricho de un grupo, sino de toda la comunidad católica, que hubo acuerdo unánime (uno consensu) y común deseo ([uno] desiderio), y que con gran pasión (magno studio) y a gritos ([magno] clamore) pidieron que la ordenación se llevase a cabo entonces $\left(\text { perfici }^{43}\right)_{\text {s }}$ sin postergarla, no fuera que fracasase la operación. La comunidad católica vivía un momento de entusiasmo y de euforia, un momento de unidad entre sus miembros presentes. De ello era expresión clara la identidad de parecer y deseo en el alma, la pasión a raudales en el alma y los gritos en el cuerpo. Esa euforia se explica por la adquisición de gran valor que acababan de hacer, aunque fuera a la fuerza. Como dice un autor, los fieles de Hipona habían conseguido sacar de su nido aquella rara avis en beneficio de su obispo ${ }^{44}$ y propio. Pero la euforia puede revelar también un cierto complejo de inferioridad que sentía frente a la comunidad cristiana rival, la donatista. Aunque quizá quepa interpretarlo también en otro sentido: el prestigio de que gozaba Agustín, unido a la penuria de pastores preparados que sufrían las comunidades católicas, hacía impensable que él no acabase siendo ordenado para alguna otra Iglesia. Pero la de Hipona les había tomado la delantera a todas. Todo ello independientemente de que el cronista haya querido embellecer eclesialmente el relato.

San Posidio añade un último apunte: "algunos vieron en sus lágrimas una señal de orgullo y, como para consolarle, le decían que la condición de presbítero, aunque él merecía más, era también un peldaño hacia el episcopado". De la errónea interpretación de sus lágrimas por parte de los entonces presentes y de su voluntad de consolarle, aunque inútilmente, habla también san Agustín en la carta dirigida a su obispo Valerio nada más ser ordenado presbítero. Pero, a diferencia de su biógrafo, el protagonista no indica cómo, limitándose a indicar que quisieron consolarle.

que no quisieran, hasta que les llega la voluntad de aceptar esa obra buena"; y en coniu. adult. 2,20,22: “... solemos presentarles la continencia de los clérigos. A estos se les obliga muchísimas veces a la fuerza a tomar esa carga...”. Aunque no lograron su intento, en el año 411, los fieles de Hipona intentaron hacer con el aristócrata Piniano lo que habían hecho años atrás con Agustín (cf. ep. 125-126). J. Gaudemet presenta varios ejemplos de ordenaciones forzadas; mantiene sus dudas sobre la fiabilidad que merecen las fuentes al respecto, pero reconoce que "Les textes requérant la libre acceptation de l'ordonné ou du consacré sont exceptionnels" (L'Eglise dans l'Empire romain [IVe-Ve siècles], Paris 1958, pp. 108-111: 109). En el epistolario agustiniano encontramos un ejemplo de un neto rechazo a ser ordenado obispo por parte del candidato propuesto por san Agustín para la Iglesia de Fussala (cf. Ep. 209,3;20*,3).

$43 \mathrm{El}$ autor utiliza dos verbos, fieri y perfici. El prefijo per del último verbo le da un valor de perfección y acabamiento; es decir, que la ordenación se llevara a cabo en ese momento.

44 Cf. G. MADEC, Augustin prêtre, 68. 
Dice así: "De allí procedían aquellas lágrimas que algunos hermanos me vieron derramar a poco de ser ordenado; ignorando las causas de mi dolor, me consolaron con buena intención, con las palabras que pudieron, que no servían para atajar el mal. Con todo lo hicieron con buena intención" ${ }^{\text {. }}$. El dato desentona de alguna manera en el conjunto del relato de san Posidio y manifiesta una cierta incoherencia, dejando en mal lugar tanto a Agustín como a los consoladores. A Agustín porque lo creen dominado por una ambición que contradiría de alguna manera su propositum; a ellos por promocionar al ministerio presbiteral a uno que creían ambicioso. La voluntad de Agustín de disculparlos puede interpretarse en el sentido de que le tocaron en parte sensible y se sintió herido. De hecho, lo que le ofrecían como consuelo era justamente una de las razones por las que él rehusaba aceptar el ministerio: significaba entrar en un cursus honorum que, aunque fuera eclesiástico, no dejaba de serlo.

\section{c) San Agustín}

La información que da san Posidio sobre san Agustín, siempre en relación con su ordenación presbiteral, no es particularmente rica. Se limita a señalar el viaje a Hipona, una razón del mismo ${ }^{46}$ y una interpretación providencialista del fracaso experimentado con la persona a la que quería convencer: "Pero de hecho no pudo diluirse en la nada lo que en todo lugar obraba la divina Providencia por medio de aquel instrumento puro, destinado a un uso honorable, útil al Señor, dispuesto para toda obra buena"47. Con relación al momento mismo de la ordenación, señala únicamente el hecho de que derramó copiosas lágrimas, y la razón de las mismas, que conoció por una confidencia de Agustín: "La realidad era que aquel varón de Dios, como él nos confesó, consideraba lo sucedido desde una perspectiva más elevada y gemía teniendo a la vista cuántos y cuán grandes peligros acarrearía a su vida el regir y gobernar la Iglesia, y por eso lloraba" ${ }^{\text {. }}$.

San Agustín confirma y completa el relato de san Posidio. De los datos que aporta, unos eran en principio verificables por sus oyentes, otros no,

45 Ep. 21,2. Sobre motivo de las lágrimas de san Agustín, cf. L. VerHeIJEN, , Perché $S$. Agostini pianse quando fu fatto sacerdote, en La ricerca di Dio. La dimensione contemplativa della esperienza agostiniana. Corso Internazionale di Spiritualità, Roma, 1-19 luglio 1979, Roma 1981, pp. 204-208.

46 Mientras san Agustín aduce dos, buscar donde fundar un monasterio y conquistar para la causa monástica al agens in rebus, san Posidio sólo menciona la segunda.

47 Posssidius, Vita, 3,5.

48 En la ep. 21,2 san Agustín añade un detalle significativo, puesto que establece una relación entre su ordenación presbiteral, sus críticas a la ignorancia del clero y sus lágrimas: "Dios quiso corregirme por haber osado reprender los pecados de muchos nautas, sin haber 
por referirse a su mundo interior. Entre los datos verificables están su llegada a Hipona siendo aún joven ${ }^{49}$, la intención de fundar un monasterio y vivir en él con sus hermanos -los que se le habían juntado en condición de siervos a Dios-, que evitaba acercarse a ciudades cuya sede episcopal se hallaba vacante, la visita al amigo al que pensaba conquistar para el monasterio, que llegó con cierta tranquilidad a Hipona porque la ciudad tenía obispo, que le apresaron y fue ordenado presbítero -peldaño hacia el episcopado-, que el obispo Valerio al conocer su propósito le donó el huerto en que fundó el monasterio, y que comenzó a reunir hermanos con el mismo buen propósito, pobres y sin nada como él, que lo imitasen ${ }^{50}$.

Otros datos resultaban no verificables para sus oyentes, a los que no les quedaba sino creer o no creer a su obispo. Él les confiesa que había abandonado toda esperanza mundana, que en consecuencia no quiso ser lo que estaba a su alcance conseguir, que no buscó su condición actual de obispo $^{51}$. Lo primero es un dato avalado en la obra del santo ${ }^{52}$; con la "esperanza mundana" y "lo que estaba a su alcance conseguir" alude a una carrera política con el consiguiente enriquecimiento ${ }^{53}$; con el tamen adversativo de que se sirve para introducir la afirmación de que no buscó ser obispo, quiere indicar que el abandono de toda expectativa de ascenso social no estuvo motivado por la perspectiva de ser jerarca eclesial ${ }^{54}$. A la presentación negativa, sigue la positiva. Un versículo sálmico le presta las palabras para indicar lo que estaba entonces en su mente: "Elegí vivir postergado en la casa de mi Dios antes que habitar en una tienda de pecadores" (Salmo 83,11). Es preferible estar en una casa, aunque sea en el lugar más humilde, a ocupar un lugar de relieve en una tienda, pues la casa tiene más consistencia que una tienda. Si esta afirmación no siempre es

experimentado aún lo que pasa en el oficio, como si yo fuera más docto o mejor. Cuando me he hallado en medio del mar, comencé a comprender la temeridad de mis reproches, aunque ya antes juzgaba peligrosísimo este ministerio. De ahí procedían aquellas lágrimas que algunos hermanos me vieron derramar...".

49 San Agustín había cumplido 36 años pocos meses antes, el 13 de noviembre. En el mundo romano la iuventus duraba desde los 30 a los 45 años.

50 "Au prix de l'acceptation de la prêtrise, et d'une assez lourde aliénation, Augustin avait atteint le bout auquel il aspirait depuis plusieurs années" (S. LANCEL, Saint Augustin, Fayard, Paris 1999, p. 219).

51 Aunque está narrando los hechos que le llevaron a la ordenación como presbítero, habla de sí como obispo, lo que era él entonces. El presbiterado aparece aquí sólo como un peldaño para ascender al episcopado.

52 Cf. Conf. 8,12,30.

53 Cf. Conf. 6,11,19.

54 Tal era la acusación lanzada contra él por el oyente maniqueo Secundino (cf.ep. Sec. 5; c. Sec. 2). 
válida, porque hay casas que amenazan ruina, no admite duda cuando se comparan la casa de Dios y las tiendas de los pecadores ${ }^{55}$. Tal es la explicación de lo que dice a continuación: "Me separé de los que aman el mundo, pero no por eso me equiparé a los que presiden las comunidades cristianas". Repite la idea de antes: si se apartó de los primeros no lo hizo con vistas a equipararse a los segundos. Sólo que ahora recurre al evangelio para dar razón de ascenso jerárquico: "En el banquete de mí Señor tampoco elegí un puesto de distinción, sino el último y humilde, pero le plugo a él decirme: 'Sube más arriba' (Lc 14,10)".

Para mostrar que no buscaba el episcopado, alega el temor que le suscitaba la simple posibilidad de ser obispo. Y para probar ese temor aduce su costumbre de evitar las ciudades en que el trono episcopal estaba vacante. Con el puesto humilde asociaba la salvación, y con el elevado, el peligro. Pero el predicador se imagina con razón que sus oyentes pueden estar haciéndose esta pregunta: "si es verdad lo que dices, ¿por qué aceptaste el ministerio sacerdotal?". Su respuesta es concluyente: "El siervo no debe llevar la contraria a su amo".

La afirmación de san Posidio de que le echaron mano y lo sujetaron y la suya propia de que le apresaron delata que Agustín opuso resistencia. Su resistencia fue física, verbal, psicológica y espiritual. La física la muestra el hecho de que no se acercó al ordenante de propia iniciativa, sino que fueron los asistentes los que "le presentaron a Valerio". La resistencia verbal no está afirmada pero la intuimos; de una parte, el habla es el medio que tiene la persona humana para mostrar su oposición; de otra, el que Valerio le regalara el terreno para levantar un monasterio deja entrever que Agustín adujo, como argumento contra la ordenación, su propósito de vivir como siervo de Dios ${ }^{56}$. Sus lágrimas prueban, a su vez, su resistencia psicológica. La más importante, sin embargo, era la resistencia espiritual de que eran prueba las demás. Estar ante el obispo ordenante no bastaba para ser ordenado; si él no hubiese aceptado, difícilmente le hubiese impuesto las manos: Una vez ante él, la violencia tenía que hacérsela a sí mismo; ésta consistía en renunciar, al menos en parte, a los proyectos que acompañaron su conversión. Y para tal renuncia tenía que encontrar una

$55 \mathrm{La}$ asociación entre este versículo del salmo y el texto del evangelio de Lucas aparece también en el comentario al salmo 83: "él elige ser postergado en la casa del Señor, pero el anfitrión del banquete llama aun puesto superior al que eligió uno inferior, y le dice: 'Sube más arriba' (Lc 14,10). Él, sin embargo, sólo elige estar en la casa del señor, en el lugar que sea, con tal de no estar fuera de ella" (En.ps. 83,15). Antes ha criticado la actitud de los donatistas que, con tal de mantener sus dignidades, se mantienen fuera de la Iglesia.

56 Aunque cabe que eso haya sido posterior a la ordenación misma. Y es lo más probable. 
motivación adecuada, a fin de que no apareciese como una traición. Hay que decir que la encontró y hasta tal punto válida que no sólo eliminaba toda sospecha de traición, sino que la aceptación del ministerio hasta resultaba ser una exigencia de la opción previa. La oportuna reflexión hizo que lo que en un primer momento justificaba su resistencia acabase exigiendo su aceptación.

En el sermón se lee textualmente: "Mas, según he dicho, el siervo no debe llevar la contraria a su amo". El predicador, sin embargo, no ha hecho previamente, al menos de forma explícita, tal afirmación. Pero sí se ha presentado como siervo de Dios que gozaba de prestigio entre ellos y, además, se ha identificado con el siervo de la parábola lucana al que el amo ordena: "Sube más arriba". Él había elegido ocupar el último lugar en la casa del Señor, pero el que le invitó al banquete, le había llamado a un puesto superior.

El pasaje evangélico recurre a las categorías de amo y siervo, sobre las que descansa toda la fuerza de la parábola. En medio de la oscuridad en que se encontraba su espíritu, el texto evangélico fue como un relámpago que le aportó la luz que necesitaba. En el momento de su regreso a la fe de la Iglesia, había optado libremente por vivir en ella como siervo de Dios. Le bastaba estar dentro de ella, aunque fuese en el último lugar. Pero no podía decir que no a su amo, el anfitrión, que le ordenaba "subir más arriba", ocupar un puesto de más categoría. Invitado al banquete del Señor, a la vez que participaba en él, tenía que servir en él ${ }^{57}$. Para el siervo no cuenta la propia voluntad, sino sólo la de su amo. Si esa es la realidad en cualquier relación amo-siervo, de ordinario relación forzada, mucho más ha de serlo en una relación nacida de la plena libertad del siervo. Una vez que ha aceptado ser siervo en la casa del amo, ya no puede elegir ni siquiera ocupar el último lugar en ella; su lugar y con ello su tarea se la asignará el amo de quien ha querido ser siervo ${ }^{58}$. Él siervo lo es a tiempo pleno; no se limita a trabajar para el amo, vive para él, y los intereses exclusivamente personales pasan, como mínimo, a un segundo lugar.

Hasta entonces san Agustín había entendido que la condición de siervo del Señor no se compadecía con la aceptación del ministerio. En su mente eran dos opciones que se excluían recíprocamente: el servicio de

57 Conf. 10,43,70: "lo como, lo bebo y lo distribuyo"

58 Cuando san Agustín habla de siervo, entiende el término en el contexto de la sociedad de entonces, sociedad esclavista, en la que el esclavo se veía privado de prácticamente todos los derechos. Por la dureza de vida que comporta y sobre todo por el envilecimiento personal que significaba, la situación de esclavo era, a lo más tolerada, nunca deseada. Nadie era esclavo por propia voluntad, salvo raras excepciones en las que, en todo caso, se buscaba eludir otra esclavitud peor. 
Dios no se armonizaba con el honor que comportaba el ministerio. Ese planteamiento no era nuevo en la Iglesia ${ }^{59}$. Pero el santo no quedó atrapado en tal estrechez de miras, sino que acertó a ver que aceptar el honor que se le proponía era una forma de ejercer el servicio. "El siervo no debe llevar la contraria a su amo": tal fue la primera reflexión del siervo de Dios ante una propuesta totalmente inesperada.

La segunda reflexión debió centrarse en la manera como el amo le había manifestado su voluntad: no de forma directa, sino a través de otros siervos suyos; en el caso concreto, los fieles de Hipona. Al respecto es significativa la estrecha vinculación que advierte el santo entre el amo y sus otros siervos, entre Dios y la comunidad creyente. Aun en la perplejidad del momento, atinó al interpretar la voluntad de la Iglesia de Hipona, surgida de una urgente necesidad, como voluntad de Dios. Su servicio a Dios acababa en servicio a la Iglesia y el servicio a la Iglesia sería su modo de ser mostrar que era siervo de Dios. No muchos años más tarde trasladaría esta reflexión a los monjes de la isla Cabrera ${ }^{60}$.

\section{Reflexiones desde el momento actual de la Iglesia}

El presupuesto para volver la mirada a aquella iglesia del norte de África de finales del siglo cuarto desde nuestro presente es la coincidencia en un problema eclesial: la escasez de vocaciones. Asumimos que las circunstancias son tan diferentes como los dieciséis siglos que separan aquel entonces de nuestro hoy. Pero creemos que esa enorme distancia no resta utilidad a la reflexión sobre lo allí y entonces acontecido.

En efecto, es un dato objetivo que la ordenación de san Agustín contribuyó a la solución del problema de las vocaciones de la Iglesia católica africana; al menos en buena medida, aunque no de forma inmediata. El santo fue promotor de un modo de vida cristiana que aportó numerosos ministros a la Iglesia. No fue solamente él quien, forzado pero voluntariamente -y valga la paradoja-, asumió el ministerio sacerdotal; a partir de su ordenación, los monasterios fundados por él o bajo su inspiración surtieron de pastores a numerosas iglesias africanas. Es siempre san Posidio quien nos informa: "A medida que progresaba la enseñanza divina, los que servían a Dios en el monasterio con san Agustín y bajo su guía comenzaron a ser ordenados clérigos para la Iglesia de Hipona". Luego

59 Cf. L. Cilleruelo, El monacato de san Agustín, pp. 163-169.

60 Cf. ep. $48,2$. 
fueron otras iglesias las que comenzaron a pedir ardientemente y a recibir obispos y clérigos: "Pues fueron en torno a una decena los hombres santos y venerables por su ascesis y enseñanza, a los que yo conocí personalmente, los que el beatísimo Agustín concedió a diversas Iglesias, algunas también importantes, que los habían pedido" 61 . Como señala el biógrafo de Agustín, si importante fue el número, no fue menor su calidad, pues cumplían bien con las cualidades intelectuales, morales y espirituales requeridas para ser dignos y celosos ministros ${ }^{62}$. El resultado fue, con frase del mismo san Posidio, que "por gracia de Dios, después de mucho tiempo, la Iglesia católica en África comenzó a levantar cabeza"63.

En la solución adecuada al problema, por parcial que fuera, intervinieron tres agentes: el obispo, la comunidad cristiana, y un fiel concreto, Agustín. Es el momento de valorar la actuación de cada uno de ellos. No se trata ahora de volver sobre lo que hicieron, sino de conocer qué está detrás de su actuar concreto.

\section{a) El obispo ${ }^{64}$}

Muchas cosas cabe decir del anciano obispo de Hipona. La primera, que fue amante de su Iglesia, por cuyo bien se preocupaba ${ }^{65}$. Sólo el amor a ella da razón de su actuar. Si donde falta el amor hay desidia, inacción y parálisis, si hay pertinente actividad es porque se ha hecho presente el amor. Y no un amor cualquiera, sino un amor de caridad, porque estaba protegido por la humildad ${ }^{66}$.

En segundo lugar, hay que añadir que era atento observador de la situación de su Iglesia -de los signos de los tiempos, se podría decir-, lo que le permitió conocer qué era lo que más necesitaba en aquel momento. Abrir los ojos a la realidad es importante, pero no es suficiente si no se sacan conclusiones acertadas. Valerio supo ver y supo concluir.

En tercer lugar, hay admitir que fue un pastor humilde, audaz y valiente a la vez. Humilde porque reconoció sus limitaciones, derivadas de su edad y deficiente capacidad para trasmitir el mensaje evangélico. Audaz para innovar, pues osó permitir a Agustín que, en presencia suya, predicase al pueblo y expusiese el evangelio, sin importarle ir contra los

\footnotetext{
61 Possidius, Vita 11,1-3.

62 Cf. también ep. 60,1.

63 Possidius, Vita,7,2. San Posidio se refiere exclusivamente a la acción de Agustín.

64 Cf. P. LANGA, Valerio de Hipona, en Augustinus 38 (1993) 303-327, sobre todo su apartado II: Rasgos de una semblanza, pp. 315-327.

65 Possidius, Vita, 5,4 .

66 Cf. s. uirg. 51,52.
} 
usos de la iglesia africana, reconociéndolos como simples tradiciones locales carentes, por tanto, de valor dogmático. Valiente porque no le importó que le llovieran las críticas de otros colegas en el episcopado que, anteponiendo su orgullo al bien de la Iglesia consideraban, una humillación escuchar el sermón de un presbítero mejor preparado que ellos. Y, como la verdad suele acabar imponiéndose, al final tuvieron que darle la razón no sólo de palabra, sino aceptando en sus iglesias, incluida la metropolitana de Cartago ${ }^{67}$, lo que antes habían criticado ${ }^{68}$. El éxito de su audaz iniciativa quedó confirmado unos dos años y medio más tarde cuando, en el concilio plenario de Hipona del 393, san Agustín recibió el encargo de exponer a los obispos allí reunidos el Símbolo de la $\mathrm{fe}^{69}$.

En cuarto lugar hay que señalar que su concepción de la Iglesia no era en absoluto clerical. Lo prueba el hecho de haber involucrado al conjunto de los fieles en la búsqueda del remedio a la urgente necesidad advertida. En el marco de una eclesiología de comunión, quería que los fieles se sintiesen miembros activos de la Iglesia, que pusiesen los dones que el Espíritu les otorgaba al servicio de la misma, no que fuesen simples ejecutores de sus órdenes.

En quinto lugar, hay que alabar su sensibilidad antes las exigencias espirituales de Agustín y las materiales, derivadas de ellas. A fin de que su servicio ministerial no significase una rotura completa con su previo compromiso religioso, en el plano personal y comunitario, le cedió el terreno para que levantase el monasterio que el nuevo presbítero tenía en mente fundar. De esa manera, el joven asceta podía asumir el ministerio presbiteral sin tener la sensación de que se traicionaba a sí mismo, o a los compañeros a los que se había unido en el servicio a Dios. La flexibilidad del obispo significó un abrir camino para que en adelante pudieran juntarse, con notable beneficio para la Iglesia, dos estilos de vida cristiana, el del monje que huye del mundo y del clérigo activo en la vida pública, que, al menos en África, hasta entonces habían corrido paralelos ${ }^{70}$.

Por último, como envolviendo todo lo anterior, hay que señalar que era un pastor que confiaba en la oración y de ella recibió el fruto esperado ${ }^{71}$.

67 Cf. ep. $41,1$.

68 Cf. Possidus, Vita, 5,5: "Después, propagándose la fama de este hecho, con el precedente de tan buen ejemplo, algunos presbíteros, recibida la facultad de sus obispos, y comenzaron a predicar a los fieles en su presencia".

${ }^{69} \mathrm{El}$ sermón, reelaborado después como obra escrita, se nos ha conservado en De fide et symbolo, que el santo publicó a petición de algunos obispos. Cf. Retr. 1,17.

${ }^{70}$ San Agustín pasa por ser quien introdujo, al menos en África, la unión entre monje y clérigo. Pero ¿de quién fue la idea, de Agustín o de Valerio?

71 Possidius, Vita 5,2. 


\section{b) La comunidad católica}

También la comunidad católica de Hipona tuvo parte activa en el remedio de su propia necesidad. En lo que nos dice san Posidio sobre ella, podemos descubrir varios rasgos de una comunidad ideal:

Una comunidad que escucha atentamente a su obispo. Éste podía estar tranquilo, en la seguridad de que no hablaba para las paredes. La comunidad de Hipona había captado bien el mensaje de su pastor referente a la necesidad de un presbítero para la ciudad.

Una comunidad que está al tanto de la vida de la Iglesia, de sus movimientos, de los dones del Espíritu en ella. En el caso concreto de la comunidad de Hipona, conocía a Agustín y lo que él representaba: una intensa piedad unida a una sólida formación teológica. Y el hecho de conocer a Agustín hace presuponer que tenía conocimiento también del grupo que convivía con él en Tagaste y de la novedad que representaba en la Iglesia africana.

Una comunidad que se implica activamente en la búsqueda de soluciones a los propios problemas. En el caso de la comunidad de Hipona, en la búsqueda de un digno candidato al presbiterado, en la línea de la exhortación del obispo, presentando de inmediato a uno de cuya preparación no cabía dudar, Agustín. Al respecto hay que distinguir entre el hecho en sí mismo y el método seguido. Es obvio que hoy resulta difícil compartir un modo de proceder tan expeditivo, aunque no hay que juzgarlo desde nuestro modo actual de pensar sino desde los usos de aquella época. Lo importante, en todo caso, es el hecho de que la comunidad actúe. Una comunidad carente de mentalidad clerical -esta puede anidar también en el conjunto de los fieles, no sólo en los clérigos-, sino plenamente eclesial; que sabe que remediar una necesidad de la comunidad misma no es asunto exclusivo de los clérigos, sino también de ella; que es consciente de que lo que redunda en bien de la Iglesia es incumbencia de toda ella.

Una comunidad que, circunstancias especiales, sabe mostrarse particularmente unida, con unidad de mente y corazón: in necessariis unitas ${ }^{72}$.

Una comunidad que no admite demoras en la ejecución de lo que juzga importante y reclama que se realice cuanto antes. Es ella la que urge

72 Íntegro, el aforismo tiene tres miembros: in necesariis unitas, in dubiis libertas, in omnibus caritas. Aunque se suele atribuir a san Agustín la paternidad, es muy posterior, pues vio la luz en el s. XVII en el contexto de los debates entre protestantes y católicos. Cf. V. BuRR, Zur Geschichte des Wahlspruches: "In necessariis unitas, in dubiis libertas, in omnibus caritas", en Unitas (Köln) 97 (1957) 123-130; J. LECLER, A propos d'une maxime citée par le pape Jean XXIII: In necessariis unitas, in dubiis libertas, in omnibus caritas, en Recherches de science religieuse 49 (1961) 549-560. 
la realización de los proyectos, tras haber puesto lo que estaba de su parte. En el caso de Hipona, que no se demorase la ordenación de Agustín.

Una comunidad que ayuda a aceptar la cruz a quien tiene que cargar con ella, no negando la palabra de apoyo y de consuelo. Fue lo que hicieron algunos fieles con Agustín, independientemente de que acertaran en el modo o no.

\section{c) Agustín}

Imprescindible para remediar la necesidad de la Iglesia de Hipona fue la aportación de Agustín. En este contexto el santo se convierte en prototipo de un modo de entender la condición de "siervo de Dios" (vida religiosa) y de un modo de entender la condición de cristiano.

Juan Pablo II hablaba de aquellos a los que una dedicación plena a la viña del Amo les llevaba a olvidarse del Amo de la viña. Pero también puede darse el caso contrario: que tanto preocuparse del Amo de la viña, se olvide la viña del Amo. En general, no se puede afirmar que fuera éste el caso de Agustín antes de su ordenación sacerdotal, puesto que en su condición de siervo de Dios se entregaba también al servicio a los hermanos, bien consciente de que el primer servicio era inseparable del segundo $^{74}$. Pero en cierto aspecto, sí que lo era. Él se había entregado en cuerpo y alma al servicio del Señor. En pro de este servicio había hecho grandes renuncias y estaba dispuesto a ser fiel a él hasta el final. Sólo que, sin advertirlo él, la suya era una fidelidad a su modo concreto de entender ese servicio. Lastrado por viejos prejuicios, aunque no sin fundamento, excluía de entrada servir en el ejercicio del ministerio presbiteral o sacerdotal. Él había elegido a quién servir y cómo servirlo, lo que en el fondo podía entenderse como un servicio a sí mismo: a las propias ideas y gustos. No había entendido que ser siervo y elegir él mismo el servicio se compaginan mal; que es el amo quien indica cómo quiere ser servido. Todo se reducía, pues, a entender correctamente lo que implica la condición de siervo. Y fue una determinada circunstancia la que le advirtió del error que guiaba su decisión, la que le llevó a tomar plena conciencia de que no es propio del siervo llevar la contraria a su amo. $\mathrm{Y}$ aquí manifiesta san

\footnotetext{
73 Aunque hoy la condición servil haya desaparecido en el plano jurídico social -cosa distinta es en el plano psicológico y moral- y ni siquiera sea atractiva como imagen, nos sirve para entender la carga de significado asociado al término de siervo y servicio.

74 Cf. Possidius, Vita, 3,2; ep. 5. La relativamente abundante producción literaria del período previo a la ordenación presbiteral es un ejemplo. Cf. D. C. AlEXANDER, Augustine's Early Theology of the Church, Peter Lang, New York 2008, p. xxx.
} 
Agustín, una vez más, su capacidad de leer en clave de fe los acontecimientos, y la seriedad de su compromiso religioso. El santo acertó a interpretar como voz de su Amo una circunstancia eclesial, detrás de la cual había una necesidad eclesial. Habiéndole puesto Dios ante los ojos esa necesidad para que contribuyese a remediarla, revisó su concepción de lo que significaba ser siervo de Dios: servirle en lo que le reclame. En vez de aferrarse a sus ideas, a su anterior planteamiento, quizá a su comodidad, supo renunciar a todo ello-renuncia de no menor exigencia-, como antes había renunciado a toda ambición mundana. Era lo que su amo le pedía, y el siervo no debe llevarle la contraria. Actuar de otra forma hubiera sido una forma sibilina de orgullo, de autocomplacencia y, en última instancia, de autoengaño. Como ya se indicó: creer que se servía a Dios y estar sirviéndose a uno mismo. En definitiva, dos principios iban a gobernar su vida en adelante. Uno, el que acabamos de señalar: el siervo no debe llevar la contraria a su amo; otro, el amo le hablaba a través de las necesidades de sus otros siervos, esto es, de la Iglesia.

A la misma conclusión llega san Agustín por otra vía: la condición de hijo de la Iglesia propia del fiel cristiano. A ella no hace referencia en su sermón a la comunidad católica de Hipona, pero apenas cabe dudar que tuvo también su peso en la propia aceptación del ministerio sacerdotal. La encontramos en la exhortación dirigida por el santo a los monjes de la isla Cabrera. Lo que importa en nuestro contexto es el principio que formula; que él lo aplique a los monjes es aquí de secundaria importancia. El fiel cristiano que ha nacido para la vida divina de Dios y de la Iglesia no debe rehusarle la ayuda cuando ella se la requiera para comunicar a otros esa misma vida que, sin su colaboración, quizá no obtendrían. "Si no hubiera habido buenos ministros que se determinasen a asistirla, vosotros mismos no hubierais encontrado modo de nacer"75. Nacer de la Iglesia para la vida divina significa tenerla a ella como madre, y la madre puede reclamar a sus hijos determinados servicios. Más aún, el hijo cariñoso no espera que ella le solicite el servicio, sino que se ofrece espontáneamente para realizarlo, aceptando servirla en lo que ella necesite. Aceptar el servicio ministerial es cuestión de amor a la Iglesia madre. Su simple presentarse como necesitada es una llamada imperiosa a quien puede prestárselo. La urgencia del servicio no admite ni perplejidades ni oscilaciones, ni falsos temo-

\footnotetext{
75 Ep. 48,2. "Sans parler expressément de lui-même, comme il vient de le faire, Augustin propose en fait de l'imiter" (A. DE VOGÜÉ, Histoire littéraire du mouvement monastique dans l'antiquité. Première partie: Le monachisme latin, vol. III: Jérôme, Augustin et Rufin au tournant du siècle (391-405), Paris 1996, p. 221.
} 
res de caer en el orgullo. No hay cabida para pretextos que pueden tener sus raíces en la comodidad76.

No hay, pues, que pensar en una llamada directa y formal. Procede traer aquí aquel texto de las Confesiones en que Agustín pregunta a la creación por Dios, respondiéndole ésta que ella no es ese Dios que busca. Entonces comenta el santo: "Mi pregunta era mi mirada; su respuesta, su belleza"77. Aplicado a nuestro caso, se puede parafrasear así: "Su llamada era su necesidad; mi respuesta, el advertirla". La necesidad de la Iglesia es en sí misma una llamada a sus hijos a remediarla, y el simple advertirla implica ya la respuesta positiva a la llamada. Siempre en el presupuesto de un amor filial a la Iglesia. Una decisión de servicio que no ha de tener en cuenta gustos personales que pueden camuflar intereses también puramente personales; que ha de surgir únicamente del amor que advierte la existencia de una necesidad que puede remediar total o parcialmente. El poder aquí tiene que acabar en querer, por encima de toda otra consideración, aún a costa de renuncias significativas. El caso de Agustín deja bien claro que en la vocación quien llama es la Iglesia y que servir a la Iglesia es, en ese caso, la única forma de servir a Dios. Aunque a otro nivel, todo fiel cristiano es siervo de Dios.

En el célebre sermón sobre los pastores, afirma san Agustín: "Si hay buenas ovejas, hay también buenos pastores, pues de las buenas ovejas salen buenos pastores"78. En boca del pastor la afirmación se refiere a la calidad moral: si las ovejas son buenas, también lo son los pastores. Pero puede interpretarse también referida a la existencia de pastores: "si hay buenas ovejas, habrá buenos pastores". Sustituyendo la imagen por la realidad, habría que decir: "si hay buenos fieles, habrá buenos ministros, pues de entre los buenos fieles no dejarán de salir buenos ministros". El buen fiel no puede no amar a la madre Iglesia. Y el amor auténtico se traducirá en servicio, porque el servir es oficio del amor: "Sea oficio del amor apacentar el rebaño del Señor, ya que fue prueba de temor haber negado

76 Ep. 243,8: "(La madre Iglesia) os concibió de Cristo, os dio a luz en sangre de mártires, os parió a la luz sempiterna... Esta madre, difundida por todo el orbe, se ve agitada por variados y múltiples ataques del error: algunos hijos abortivos ya no dudan en luchar contra ella con armas mortíferas. Por la cobardía y modorra de algunos que tiene que llevar en su regazo, se lamenta de que sus miembros se resfrían en muchos lugares y se hace menos capaz de ayudar a sus pequeños. ¿Cómo podrá lograrlo, sino por otros hijos, por otros de sus miembros en cuyo número te encuentras tú, a los que pide el auxilio justo y debido. ¿Olvidarás sus necesidades, amparándote en palabras que te dicta la carne?" (Ep. 243,8).

77 Cf. Conf. 10,6,9.

78 S. 46,30 . 
al Pastor»'/y. Pero no cualquier servicio, sino el que ella le solicite. Su misma condición de buen fiel cristiano le llevará a no elegir él la forma de servirla, sino a aceptar el que ella le reclame, que no será otro que el que ella necesite. El criterio personal cederá a favor del criterio de la Iglesia, siempre que ésta sea sinceramente amada; siempre que se la sienta como la madre que alumbra para la vida divina, y siempre que se aprecie en su justo valor esta vida divina. Porque quien no aprecia el don, tampoco aprecia a quien lo otorga, y si no aprecia a quien lo otorga, tampoco se pondrá desinteresadamente a su servicio.

La antigüedad cristiana nos dejó ejemplos admirables de esas vocaciones que nos equivocaríamos si las considerásemos forzadas. Pues, si algo faltó en ellas, no fue precisamente la libertad. A un rechazo inicial siguió una libertad más plena y precisamente más plena porque estaba precedida por ese rechazo. Aceptar algo que espontáneamente se rechaza sólo es posible desde una libertad superior, surgida de una consideración más alta que la que fundaba el rechazo. El rechazo puede venir de una psicología débil, la aceptación sólo es posible desde un convencimiento firme; aquel de motivaciones humanas, esta de motivaciones de fe; aquel de la voluntad de complacerse a uno mismo, esta de la voluntad de complacer a la Iglesia-madre o a Dios-Padre, que nos han engendrado para la vida divina.

En síntesis final, el ejemplo tomado de Hipona a primeros del año 391 nos indica el problema de las vocaciones se encauzó gracias a que hubo un pastor, una comunidad y un fiel que supieron responder a la llamada angustiosa de la Iglesia. Es sólo un ejemplo, pero puede resultar paradigmático. En todo caso, puede servir para la reflexión.

Pío de LuIs

Estudio Teológico Agustiniano Valladolid

${ }^{79}$ Io. eu. tr. 123,5; cf. Presbyterorum ordinis 14. 